\title{
CONSIDERATION OF THYROID DYSFUNCTION FOR MENSTRUAL ABNORMALITIES IN PREMENOPAUSAL WOMEN
}

\author{
Anita Ramesh Annaldasula ${ }^{1}$, Shivakrishna Gouroju *2.
}

${ }^{1}$ Associate professor, obstetrics \& Gynecology, Shanthiram Medical College, Nandyal, Kurnool, Andhra Pradesh, India.

2 Tutor in Biochemistry, Andaman and Nicobar Island Institute of Medical sciences, Port Blair, India.

\section{ABSTRACT}

Abnormal Uterine Bleeding (AUB) is one of the most frequently encountered conditions in women, it has been recognized that thyroid dysfunction may have profound effects on the female reproductive system, menstrual disturbances and cause of excessive puberty bleeding. Hence this study is to evaluate the thyroid function in patients having abnormal uterine bleeding from age group of 20 to 40 yrs with 100 AUB patients which will help in further management and also know the prevalence of thyroid disorders in abnormal uterine bleeding. Out of 100 patients 42 women with thyroid abnormality, heavy menstrual bleeding was seen in 21 (50\%) women, 11 (26.19\%) had Polymenorrhagia, 10 (23.81\%) had Oligomenorrhoea, in women with hypothyroidism (30 women) was heavy menstrual bleeding in 17 (56.67\%) women, $6(20 \%)$ had Oligomenorrhoea, 7 (23\%) had Polymenorrhagia, and in 18 women with hyperthyroidism, 10 (55.56\%) had heavy menstrual bleeding, $4(22.22 \%)$ had oligomenorrhoea, $4(22.22 \%)$ had Polymenorrhagia. So that clinicians should consider that thyroid dysfunction is as an important associated factor for menstrual abnormalities even in premenopausal women. It is important to screen all women for thyroid abnormality who are presenting with AUB especially with nonstructural causes of AUB. Correction of thyroid abnormalities also relieves AUB. This will avoid unnecessary hormonal treatment and surgery.

KEY WORDS: Abnormal Uterine Bleeding, thyroid dysfunction, heavy menstrual bleeding, Oligomenorrhoea, Polymenorrhagia.

Address for correspondence: Dr. Shivakrishna Gouroju, Tutor in Biochemistry, Andaman and Nicobar Island Institute of Medical sciences, Port Blair, India. E-Mail: drmbankar@gmail.com

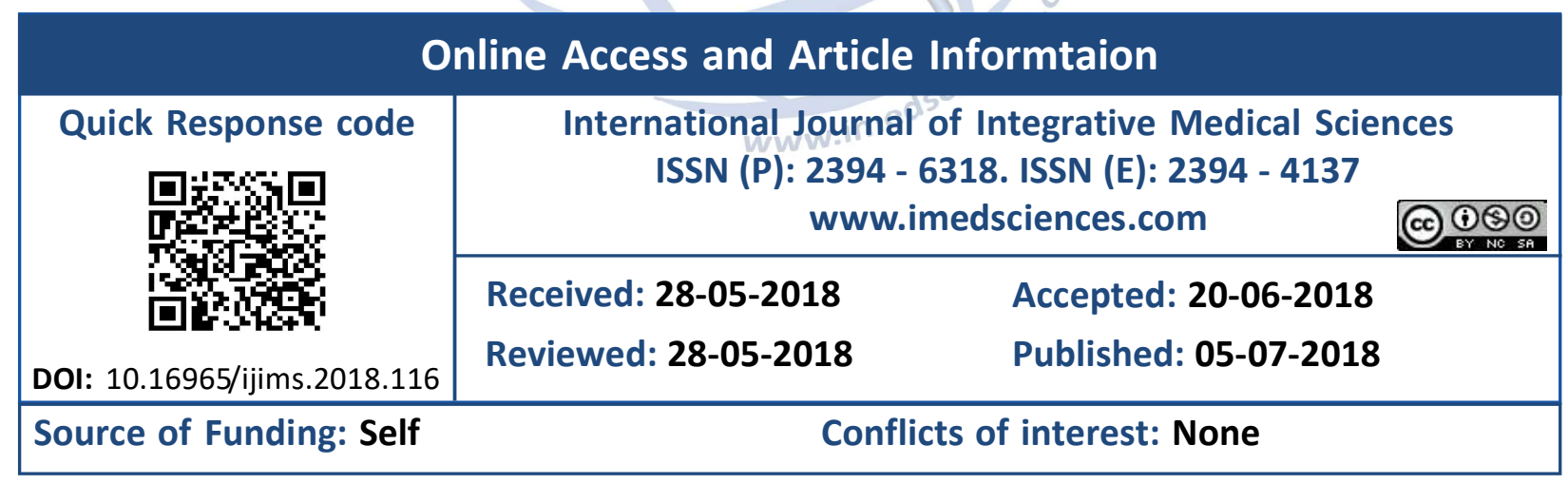

\section{BACKGROUND}

Abnormal Uterine Bleeding (AUB) is one of the most frequently encountered conditions in gynecology. It has long been recognized that thyroid dysfunction may have profound effects on the female reproductive system. Thyroid disorders are 10 times more common in women than in men [1]. Majority of the cases of subclinical hypothyroidism easily pass unrecognized. The prevalence of subclinical hypothyroidism is as high as 9.5 percent in women [2].
Danese MD et al recommend hypothyroidism is frequent enough to warrant consideration in older women [3]. Ely et al state that any irregular bleeding in non pregnant patient and in non pregnant patients with menorrhagia TSH should be evaluated [4].

Menstrual irregularity was significantly more frequent in hypothyroidism or hyperthyroidism as compared to control cases and in more than $45 \%$ of cases this preceded the appearance of goiter or clinical sign and symptoms [5-7]. 
A prevalence of $22 \%$ of early hypothyroidism by thyrotropin releasing hormone test in menorrhagic women, that is much higher than that found in general population [8]. Hypothyroidism was the second common cause of excessive puberty bleeding. Adolescents with hypothyroidism tend to have milder symptoms than older patients, the cause of excessive bleeding in hypothyroidism remains in the realm of speculation [9]. Both hypothyroidism and hyperthyroidism may result in menstrual disturbances. With hyperthyroidism, hypomenorrhea and amenorrhea are more frequent complaints, and menorrhagia is noted in approximately 5 percent. With hypothyroidism, women commonly present with menorrhagia, metrorrhagia and anovulatory type of dysfunctional uterine bleeding. Hence this study is to evaluate the thyroid function in patients having abnormal uterine bleeding from age group of 20 to 40 yrs which will help in further management and also know the prevalence of thyroid disorders in abnormal uterine bleeding.

\section{MATERIALS AND METHODS}

This prospective study conducted in the department of Obstetrics and Gynecology, Santhiram medical college and hospital, Nandyal. A.P. on all 100 women in the age group of 20 to $40 \mathrm{yrs}$ attending or admitted in the hospital during the period from October 2017 to March 2018, with abnormal uterine bleeding and Ultrasound showing normal uterus and ovary finding were included in the study. Patient suffering with diagnosed case of ovarian cyst, uterine fibroid, polyp, adenomyosis, endometriosis and malignant (endometrial and cervical) tumors, goiter, carcinoma thyroid. Patients who are on drugs or hormones, IUCD users, with overt clinical symptoms of thyroid dysfunction, history of bleeding disorders (haemophilia, von Willebrand's disease), Pelvic infections including endometritis, PID, PCOD, Patient on sex steroids were excluded from the study. The data will be collected using a prepared proforma meeting the objectives of the study by means of personal interview of the patient after taking informed consent. The descriptive statistical analysis was performed using SPSS software 11.5 VERSION.

Procedure: The study protocol included a thorough history taking regarding age, bleeding pattern, onset, duration, quantity of bleeding and complaints related to thyroid dysfunction were noted in detail. A thorough clinical examination including general physical examination, neck examination, systemic and gynecologic examinations were carried out. All the recruited patients were subjected to routine investigations like hemoglobin, ESR, LFT, RBS, complete urine examination, bleeding time, clotting time, chest $x$-ray, ultrasound abdomen and pelvis, pap smear, endometrial biopsy. All patients were subjected to T3, T4 and TSH. T3 and T4 were assayed by competitive chemiluminescent immunoassay. TSH was estimated by ultra- sensitive fully automated ADV1A centaur, using two sites and which, and chemiluminescent immunoassay and analyzed.

Reference values: Serum T4 $-60-120 \mathrm{ng} / \mathrm{ml}$, Serum T3 $-0.8-16 \mathrm{ng} / \mathrm{ml}$, Serum TSH $-0.5-5$ $\mathrm{mU} / \mathrm{ml}$

\section{RESULTS}

Table 1: Thyroid abnormality and menstrual pattern.

\begin{tabular}{|c|c|c|}
\hline Menstrual pattern. & Numbers & $\%$ \\
\hline $\begin{array}{c}\text { Heavy menstrual } \\
\text { bleeding }\end{array}$ & 21 & 50 \\
\hline Oligomenorrhoea & 10 & 23.81 \\
\hline Polymenorrhagia & 11 & 26.19 \\
\hline Total & 42 & 100 \\
\hline
\end{tabular}

Fig. 1: Thyroid abnormality and menstrual pattern.

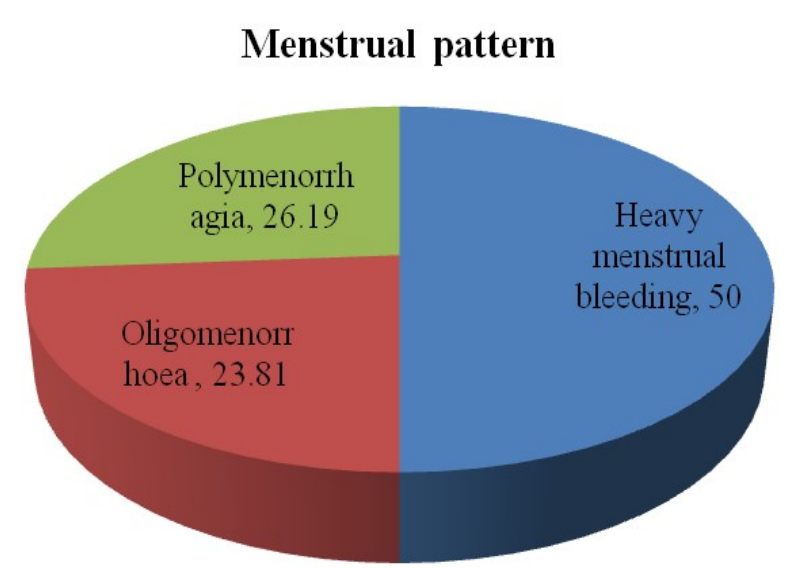

A total of 100 patients in premenopausal age group with AUB were recruited in the present study age group of 20 to 40 yrs mean age group is $26.42 \pm 4.38$ years. In 100 women with AUB, 42 (42\%) women had thyroid abnormality. AUB - Thyroid abnormality: Out of 100 women with AUB 52 (52\%) were euthyroid, 30 (30\%) 
were hypothyroid and 18 (18\%) were hyperthyroid. Thyroid abnormality - Menstrual pattern: Among 42 women with thyroid abnormality, heavy menstrual bleeding was seen in 21 (50\%) women, 11 (26.19\%) had Polymenorrhagia, 10 (23.81\%) had Oligomenorrhoea (Table 1 and Figure 1).

Hypothyroidism - Menstrual pattern: The frequent menstrual abnormality in women with hypothyroidism (30 women) was heavy menstrual bleeding in 17 (56.67\%) women, $6(20 \%)$ had oligomennorhoea, 7 (23\%) had polymenorrhagia (Table 2 and Figure 2).

Table 2: Menstrual pattern of hypothyroidism.

\begin{tabular}{|c|c|c|}
\hline Menstrual pattern. & Numbers & $\%$ \\
\hline $\begin{array}{c}\text { Heavy menstrual } \\
\text { bleeding }\end{array}$ & 17 & 56.67 \\
\hline Oligomenorrhoea & 6 & 20 \\
\hline Polymenorrhagia & 7 & 23 \\
\hline Total & 30 & 100 \\
\hline
\end{tabular}

Fig. 2: Menstrual pattern of hypothyroidism.

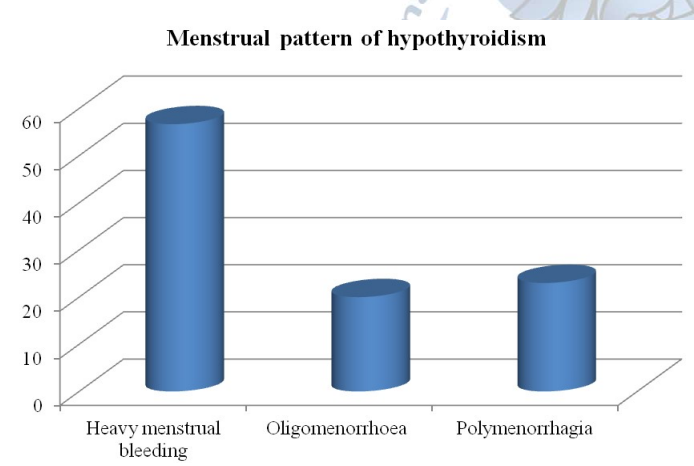

Table 3: Menstrual pattern of hyperthyroidism.

\begin{tabular}{|c|c|c|}
\hline Menstrual pattern. & Numbers & $\%$ \\
\hline $\begin{array}{c}\text { Heavy menstrual } \\
\text { bleeding }\end{array}$ & 10 & 55.56 \\
\hline Oligomenorrhoea & 4 & 22.22 \\
\hline Polymenorrhagia & 4 & 22.22 \\
\hline Total & 18 & 100 \\
\hline
\end{tabular}

Fig. 3: Menstrual pattern of hyperthyroidism.

Menstrual pattern of hyperthyroidism

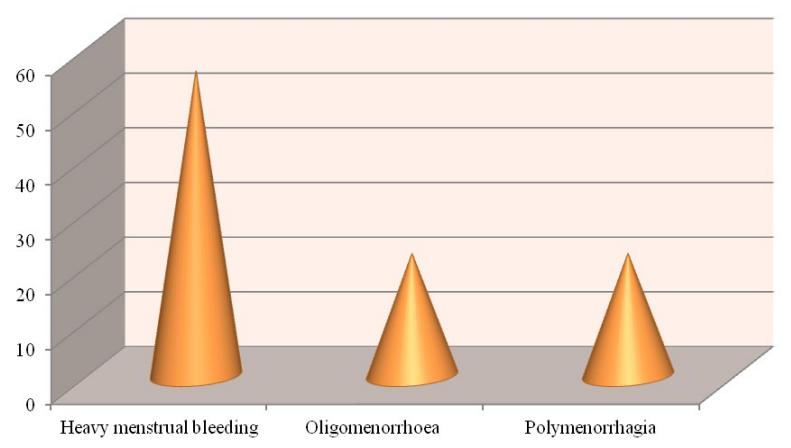

Int J Intg Med Sci 2018;5(6):650-54. ISSN 2394 - 4137
Hyperthyroidism - Menstrual pattern: Out of 18 women with hyperthyroidism, 10 (55.56\%) had heavy menstrual bleeding, 4 (22.22\%) had oligomenorrhoea, 4 (22.22\%) had polymenorrhagia (Table 3 and Figure 3).

AUB - Structural abnormalities: In a total of 100 patients with AUB, 39 (39\%) had structural abnormalities in uterus and ovaries. $18(18 \%)$ had adenomyosis, 12 (12\%) had ovarian cysts, 9 (9\%) had the fibroids (Table 4 and Figure 4).

Table 4: Structural abnormalities in AUB.

\begin{tabular}{|c|c|c|}
\hline $\begin{array}{c}\text { Structural } \\
\text { abnormality }\end{array}$ & Numbers & $\%$ \\
\hline Adenomyosis & 18 & 18 \\
\hline Fibroid & 9 & 9 \\
\hline Ovarian cyst & 12 & 12 \\
\hline
\end{tabular}

Fig. 4: Structural abnormalities in AUB.

Structural abnormalities in AUB

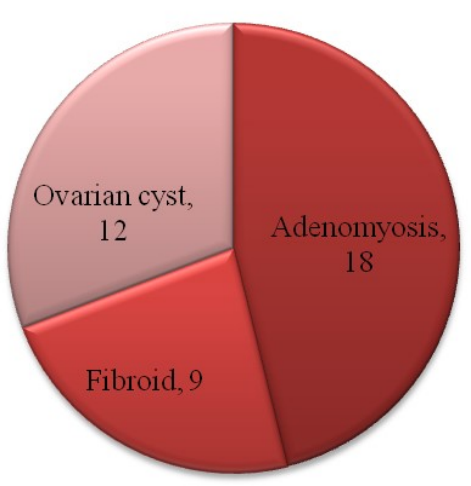

Hypothyroidism - Structural abnormality: In 30 women with hypothyroidism, 7 (23.33\%) had adenomyosis and $3(10 \%)$ had fibroid.

\section{DISCUSSION}

Irregular menstrual with thyroid abnormality are very common in women and even precede the onset of thyroid abnormalities that is both hypo and hyperthyroidism [8]. Menstrual irregularities ranges from oligomenoorhoea to menorrhagia [9].

A total of 100 patients in premenopausal age group with AUB were recruited in the present study age group of 20 to 40 yrs mean age group is $26.42 \pm 4.38$ years. In 100 women with AUB, 42 (42\%) women had thyroid abnormality. AUB Thyroid abnormality: Out of 100 women with AUB 52 (52\%) were euthyroid, 30 (30\%) were hypothyroid and 18 (18\%) were hyperthyroid which is near with study done by Neelu Sharma 
et al. (2012) (22\% hypo, 14\% hyper, 64\% euthyroid) [10].

Thyroid abnormality- Menstrual pattern: Among 42 women with thyroid abnormality, heavy menstrual bleeding was seen in 21 (50\%) women, 11 (26.19\%) had Polymenorrhagia, 10 (23.81\%) had Oligomenorrhoea (Table 1 and Figure 1) which is near to study done by Padmaleela et al. and Byna $P$ et al $[11,12]$.

In present study group $\mathrm{HMB}$ was found in 17 (56.67\%) women, 6 (20\%) had oligomennorhoea, $7(23 \%)$ had polymenorrhagia in hypothyroid women which is closely related to study done by Padmaleela et al. (HMB in $53.3 \%$, polymenorrhagia in $20 \%$, oligomenorrhoea in $20 \%$ ) [11]. In present study group HMB was found in 10 (55.56\%) of hyperthyroid women which is related to study done by Padmaleela et al. (HMB in 42.8\%). 4 (22.22\%) had oligomenorrhoea, $4(22.22 \%)$ had polymenorrhagia [11]. In Dipak Lahiri et al. study of 189 hypothyroid women to find out their menstrual pattern and fertility status, as many as 91 patients (71.09\%) had subclinical hypothyroidism; $46.87 \%$ had normal menstrual pattern. Menstrual aberrations included mainly oligomenorrhoea, hypomenorrhoea, menorrhagia and secondary amenorrhoea. Oligomenorrhoea was the commonest menstrual abnormality found mainly in early age group women. Menorrhagia was commoner in later age group. In this study author has commented that "as majority of cases are subclinical, it is essential to evaluate thyroid function in all women with intractable menstrual disorders, infertility and recurrent pregnancy loss [11].

In present study group 39 (39\%) had structural abnormalities in uterus and ovaries but in the Nellore region Byna P et al found only 11 (20\%) had structural abnormalities in uterus and ovaries. In the present study 18 (18\%) had adenomyosis, a study done by Bhavani et al. [14] in that they found $8.3 \%$ adenomyosis, Byna $P$ et al [12] found $9 \%$.

In present study $9(9 \%)$ patients had fibroids but in the Nellore region study done by Byna $\mathrm{P}$ et al [12] showing 5.4\% and in Gowri M et al. [15] found $2.4 \%$ and 12 (12\%) patients were resent with ovarian cyst, Byna P et al [12] showing 5.4\% had ovarian cyst and in Gowri M et al. [15], 1.7\% Int J Intg Med Sci 2018;5(6):650-54. ISSN 2394 - 4137 showed which are lesser than my findings.

In present study group, 7 (23.33\%) women with hypothyroidism had adenomyosis and $3(10 \%)$ had fibroid. But in the study done by Byna P et al. from Nellore region they found $25 \%$ women with hypothyroidism had adenomyosis and $8.33 \%$ had fibroid [12].

\section{CONCLUSION}

Thyroid dysfunction should be considered as an important associated factor for menstrual abnormalities even in premenopausal women. It is important to screen all women for thyroid abnormality who are presenting with $A U B$ especially with non-structural causes of AUB. Correction of thyroid abnormalities also relieves AUB. This will avoid unnecessary hormonal treatment and surgery.

\section{REFERENCES}

[1]. Berek JS, Adarshi EY and Hillard PA. In endocrine disorders. Novaks Gynaecology, $12^{\text {th }}$ Edn. William \& Wilkins, Gopson paper Ltd., Noida. 2001; pp.864.

[2]. Rebecca Abraham, V Srinivasa Murugan Et al., : Thyroid disorders in women of Puducherry, Indian journal of clinical biochemistry.2009:24:52-9.

[3]. Danese MD, Powe NR, Swain CT, Ladenson PW. Screening for mild thyroid failure at the periodic health examination. A decision and Cost effective analysis. JAMA 1996; 276: 285.

[4]. John W.Ely M.D.,MSPH, Colleen M. Kennedy, MD, MS, Elizabeth C. Clark, MD et al., :Abnormal uterine bleeding: A management algorithm. Department of Obstetrics and Gynaecology, University of lowa Carver College of Medicine, Lowa Cirty.IA, Pg. 1-17.

[5]. Joschi JV, Bhandarkar SD, Chadha M, Balaiah D, Shah R. Menstrual irregularities and lactation failure may precede thyroid dysfunction on goiter. $J$ Postgrad Med 1993; 39(3): 137-41.

[6]. Wilansky DL, Griesman B. Early hypothyroidism in patients with menorrhagia. Am J Obstet Gynaecol. 1989; 160:673-7.

[7]. Jayadey Mukherjee and NN Roy Chowdhary.A review of 70 cases of puberty menorrhagia. J Obst and Gynaec of India. 1986 pp.121.

[8]. Pushpa S, BikhaRam D, Razia MA, ZulfiquarAli SS, Tarachand D, Ishrat B. Impaired thyroid functions in patients with menstrual disturbances (An experience of a private clinic). World Appl Sci J. 2009;7(4):538-42.

[9]. Sruthi T, Shilpa SB, Gopal N. Prevalence of hypothyroidism in patients with provisional diagnosis of DUB. J Evol Med Dent Sci. 2014;3(11):2967-72.

[10]. Sharma N, Sharma A. Thyroid profile in menstrual disorders. JK Sci. 2012;14(1):14-7. 
[11]. Padmaleela K, Vimala T, Lavanya KM, Kiranmai D. Thyroid disordrs and dysfunctional uterine bleeding (DUB) among reproductive age group women. A cross sectional study in a tertiary care hospital in Andhra Pradesh, India. Int J Med Pharm Sci. 2013;4(1):41-6.

[12]. Byna P, Siddula S, Kolli S, Shaik MV. Thyroid abnormality in perimenopausal women with abnormal uterine bleeding. Int J Res Med Sci 2015;3:3250-3.

[13]. Dipak Lahiri, Anian Dasgupta, Sarmila Kundu. Menstrual pattern and fertility status of hypothyroid women. J Obst and Gynaec of India 1996; 47: 663.
[14]. Bhavani N, Avanthi S, Aradhana G, Sangeeta C, Prasannakumar VS. A study of correlation between abnormal uterine bleeding and thyroid dysfunction. Int J Recent Trends in Sci Technol. 2015;14(1):131-5.

[15]. Gowri M, Radhika BH, Harshini V, Ramaiaha R. Role of thyroid function tests in women with abnormal uterine bleeding. Int J Reprod Contracept Obstet Gynecol. 2014;3(1):54-7.

How to cite this article: Anita Ramesh Annaldasula, Shivakrishna Gouroju. CONSIDERATION OF THYROID DYSFUNCTION FOR MENSTRUAL ABNORMALITIES IN PREMENOPAUSAL WOMEN. Int J Intg Med Sci 2018;5(6):650-654. DOI: 10.16965/ijims.2018.116

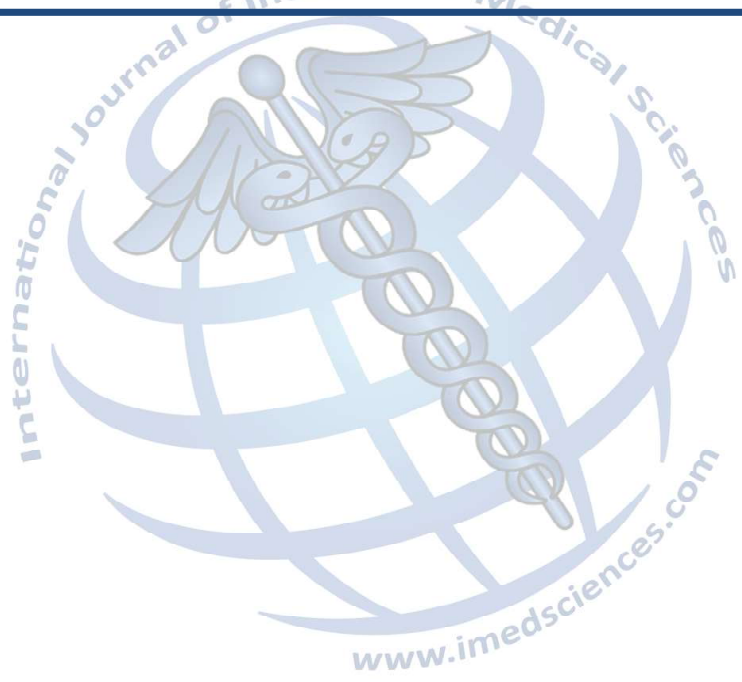

